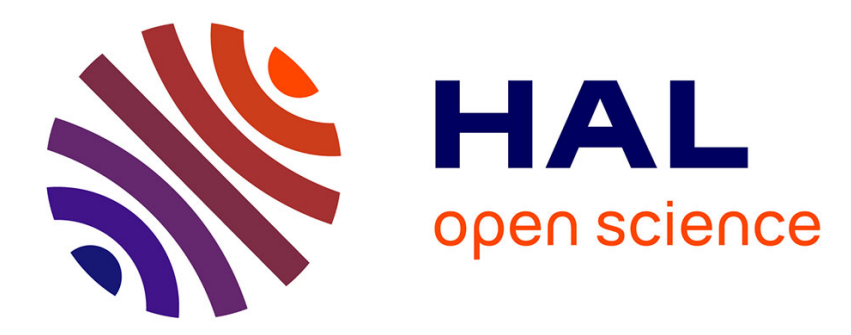

\title{
Theatre-based learning to foster corporate legacy change
}

Irena Descubes, Tom Mcnamara

\section{To cite this version:}

Irena Descubes, Tom Mcnamara. Theatre-based learning to foster corporate legacy change. 2015. hal-01205246

\section{HAL Id: hal-01205246 \\ https://hal-rennes-sb.archives-ouvertes.fr/hal-01205246}

Preprint submitted on 29 Sep 2015

HAL is a multi-disciplinary open access archive for the deposit and dissemination of scientific research documents, whether they are published or not. The documents may come from teaching and research institutions in France or abroad, or from public or private research centers.
L'archive ouverte pluridisciplinaire HAL, est destinée au dépôt et à la diffusion de documents scientifiques de niveau recherche, publiés ou non, émanant des établissements d'enseignement et de recherche français ou étrangers, des laboratoires publics ou privés. 


\title{
Theatre-Based Learning to Foster Corporate Legacy Change
}

\author{
Irena Descubes - Tom McNamara
}

\section{Structured Abstract:}

Purpose: The current literature relating New Public Management (NPM) with effective organizational change is mostly focused on how the private sector's managerial methods and tools can be better applied to the public sector by "modernizing" it, allowing for a more rational use of resources and improved economic performance. The success with regards to the implementation of major organizational change is increasingly measured by standardized quality management tools, used mainly by the private sector, such as balanced scorecards or performance-related salaries. While these managerial devices are, for the most part, understood and readily accepted by internal stakeholders in the private sector, studies have shown that they can trigger unexpected and unwanted dynamics in public companies, which often have a larger mandate, both in scope and purpose, than their private counterparts. An increasing number of scholars argue that private sector managerial tools and methods cannot be merely imposed upon employees in the public sector due to the possible generation of resistance or detriment to the intended outcomes of the organizational change desired.

Design/methodology/approach: In this paper we study the case of Électricité Réseau Distribution France (ERDF), a $€ 12$ billion French organization that was created as a result of the deregulation of the market for electricity in Europe that started at the end of the 1990s. ERDF is a $100 \%$ owned subsidiary of EDF (Électricité De France), the French national electric company. ERDF is responsible for managing $95 \%$ of the electricity distribution network in France, and its stated goal is to ensure equal access to the national electrical grid, i.e. a "level playing field" for all. Therefore, while it has had to maintain good relations with its parent company (EDF), it also had to rapidly adopt a more profit-oriented corporate culture and foster relationships with new and alternative suppliers of electricity. To help ERDF achieve this goal a study was done using a management training technique that relies on Theatre-Based Learning theory and practice. A critical component of this approach was the use of "meta-language", i.e. a phenomenon that allows for expressions other than those normally found through verbal exchanges. This can generate dialogue that is critical to the implementation of change. Meta-language has been successfully used in the past with people who have undergone stress or who have been exposed to stressful situations or environments (e.g. people living in economically challenged areas, or under repressive regimes, or who have been addicted to drugs). This study used Theatre-Based Learning theory and practice, in conjunction with meta-language, for a public company undergoing major organizational change. The findings show that this method generated a reflective process in which participants developed an enhanced sense of ownership and interest in the targeted organisational structure. An investigation was carried out over three months involving 70 ERDF employees taking part in "theatre-based learning" workshops. These workshops created "forums" in which the participants were able to better interact with each other, as well as develop frameworks and tools better adapted to the desired organizational culture. This study used the following experiential and transformative theatrical arts-based processes/techniques: (i) Support projective techniques revealing tacit and embodied collective knowledge as well as individual inner feelings and hidden unconscious processes in the preparatory stage of the present training scheme. (ii) Critical reflection: identifying and 
raising awareness of social / inter-professional structures inside the organisation in order to discover various process and structural overlaps. (iii) Generative questioning: exploration and understanding of how individuals inside the organisation experience various aspects of issues or phenomena.

Findings: The training initiative resulted in a noticeable improvement with regards to (i) The understanding of what employees believe and what they identify as being a sustainable and satisfactory customer service relationship. (ii) The ability of employees to provide solutions / products / services specifically tailored to individual customers that will result in better value and a more positive experience for the client. (iii) Employee motivation as it relates to getting actively involved in the evolution of ERDF's corporate culture and contributed to the creation of an esprit de corps. This study led to the participants collectively developing ERDF inhouse practices and tools which were then shared and further improved upon with other internal stakeholders. Among the most noticeable tools and methods adopted ex post were the following: (i) Creation of an open-source portfolio of sales and after-sales selling points stemming from recognized in-house best practices. (ii) Development of a knowledge transfer system operated by volunteer trainers recruited from among ERDF employees. (iii) Organization of regular collective debriefing sessions so to avoid "mission creep" and employees becoming too attached to one particular customer, possibly losing sight of overall corporate objectives. (iv) Development of a customer based problem solving decision matrix.

Originality/Value: The value of this paper is that it enlarges the scope with regards to the application of experiential and transformative learning techniques to a public sector enterprise undergoing a major organizational change due to the application of a NPM framework.

Keywords: theatre-based learning techniques, ERDF, organizational change

Article Classification: L29, L39, M14

Paper Category: Research paper/Case study 


\section{Introduction}

Starting in the late 1990s, the market for electricity in the European Union (EU) was slowly deregulated (EU directive 96/92/EC), with the goal being to introduce liberalization and increase competition. As a result, customers were eventually given the right to choose their electricity supplier and the ability to change suppliers easily. A ruling issued in 2003 (EU directive 2003/54/EC) forced all EU countries to "unbundle" transmission systems from transmission system operators. In France, this resulted in the generation of electricity and the distribution of electricity being broken into 2 different activities run by separate companies. EDF (Electricité de France), the French historical public provider of both production and distribution of electricity, has kept the activities linked to the generation of electricity, while a $100 \%$ wholly owned subsidiary, ERDF, was created in 2008 to manage the electrical distribution network. ERDF is responsible for managing $95 \%$ of the electricity distribution network in France, ensuring quality and safety to the 35 million customers that it serves. The distribution network belongs to local municipalities who then subcontract the management of the transmission lines (almost 1.3 million kilometres in total) to ERDF. With turnover of over $€ 12$ billion in 2011, its stated mission is twofold; 1) ensure the continuity and quality of electrical service and 2) provide for the non-discriminatory access to the electrical distribution network in France. The organization has 36,770 employees, spread out over 8 different regions. One region in particular, ERDF-West (ERDF-Ouest), will be the focus of this case study.

Shortly after its establishment, ERDF faced a major management challenge as it was required to carry a new "ethos", different from that of EDF, its nominal parent company. EDF being the dominant national electric company has developed a clearly more competitive and sales oriented corporate culture. As ERDF has got a mandate to provide a level playing field to all new comers who wish to sell electricity in France, it is required to ensure equal access to the national electrical grid, i.e. a "level playing field" for all. Nevertheless, both its white collar and blue collar workers were asked to acquire a more professional outlook, i.e. change their corporate culture from that of a public service company that doesn't necessarily have to generate a profit and can take a long term view regarding business development, to that of a more customer-service oriented and profitable one. As a result, its employees had to acquire new skills and competences that would allow them to become more commercially aware and foster relationships with new and alternative suppliers of electricity, while maintaining good relations with its EDF, its parent company.

Management believed that it needed to provide its workforce with training, skills and understanding that would:

- Instil in them a deeper appreciation for customer service and customer satisfaction.

- Allow them to be able to empathise and engage in active listening with the customer, being able to understand and, where possible, anticipate their needs.

- Increase the value that their activities provided and further develop employees' skills and competences when handling complex situations, especially related to the key B2B client accounts that are at the core of ERDF's business.

ERDF wanted to find a way to take advantage of the reputation and accumulated corporate knowledge and experience that it had acquired from being a part of EDF - something that 
could very well be considered as a "transformational asset" (Soparnot, 2012) - while at the same time improving customer satisfaction and customer relations as well as to instil a new corporate spirit to its workforce. Through the use of role-play and imagination theatre-based facilitation, it was hoped that new outlooks and perceptions would be arrived at for providing innovative solutions and courses of action that otherwise would not have been achieved.

In October of 2011, ERDF decided to partner with the ESC Rennes School of Business (ESC Rennes), France, in a custom designed training initiative. The programme used the innovative concept of "theatre-based" learning. With this method, participants use narrative and theatre to identify and conceptualize a problem. Through the use of role-play and imagination, it was hoped that new outlooks and perceptions would be arrived at for providing innovative solutions and courses of action that otherwise would not have been achieved. A key and vital component of this custom designed initiative was the use of professional actors. The field workshops and training sessions were assisted by the theatre company "Puzzle Compagnie" based in Rennes, France. Two actors were fully engaged in the change management project.

The present paper investigates a concrete process of harnessing organizational change thanks to TBL at ERDF (Électricité Réseau Distribution France) that took place after the third round of deregulation legislation was adopted with regards to electricity markets in the EU in July 2009 (EU Directive 2009/72/EC).

\section{Literature Review}

The current literature (Fernandez and Moldogaziev, 2013, 2011; Jääskeläinen and Lönnqvist, 2011) relating New Public Management to effective organizational change is mostly focused on how the private sector's managerial methods and tools can be better applied to the public sector by "modernizing" it, allowing for a more rational use of resources and improved economic performance. A key component has been the use of "employee empowerment programs" (Bowen and Lawler, 1995) which quite often are put in place in in the hopes that they will improve performance by finding innovative ways of correcting deficiencies in the delivery of services by reconfiguring work processes with active employees' participation, both in terms of their design and operational delivery. The success with regards to the implementation of major organizational change is increasingly measured by standardized quality management tools, used mainly by the private sector, such as balanced scorecards or performance-related salaries (Biron and Bamberger, 2010). While these managerial devices are, for the most part, understood and readily accepted by internal stakeholders in the private sector, studies have shown (Kim, 2002; O'Flynn, 2007) that they can trigger unexpected and unwanted dynamics in public companies, which often have a larger mandate, both in scope and purpose, than their private counterparts. An increasing number of scholars argue (Halvorsen et al., 2005; Perry et al., 2006; Walker et al., 2011) that private sector managerial tools and methods cannot be merely imposed upon employees in the public sector due to the possible generation of resistance or detriment to the intended outcomes of the organizational change desired, especially in cases that concern companies undergoing a major status change from public to private or semi-private status. When exploring organisational situations with complex dynamics generated by historic and newly created organizational structures and players, new forms of action research are increasingly appreciated especially by the practitioners' community. Action research differs from the traditional academic research in terms of scope and focus. While academics mostly continue to produce discipline- and specific science-based knowledge, the participatory action researchers expand their interest 
into context-driven, problem-oriented, and interdisciplinary knowledge production (Gibbons et al., 1994).

The implementation of new managerial patterns in the context of existing structural frameworks present a major challenge for all stakeholders and may generate tensions and frustrations. That is why it is important to provide them with an interpretative action set of tools and processes that facilitate an organisational learning and practice-based innovation (Barry and Meisiek, 2010). In the case study discussed in this paper, the research team partners (comprised of ERDF Management and an action research team from the ESC Rennes School of Business) developed a Theatre-Based Learning (TBL) framework that offers an effective strategy for the creation of creation of opportunities for reflection that reveal the dynamics of innovation, both in terms of what enables and what prevents innovative managerial practices (Vince and Reynolds, 2009; Gherrardi, 2006). Despite its epistemological potential in organizational learning and change, TBL has not been widely used as a method for affecting organizational change in a European context, as opposed to its use in Anglo-Saxon countries, where it has received more attention and investigation (Beck et al. 2011; Nisker, 2008; Saldaña, 2008, 2009; White \& Belliveau, 2010, 2011). The present participatory action research is therefore based on the assumption that workers, be they "white" or "blue" collar, continuously reframe and reinterpret organizational processes, hence they implicitly are involved in an innovation process. In order to generate an explicit and actionable corpus of knowledge, a TBL was determined as being the most appropriate approach and framework for harnessing organizational change. It is based on post-Boalian theatre practices (Boal, 1985) which apply various theatrical techniques, allowing participants to interpret existing organizational situations and conflicts (i.e. understand them in terms of "as they are today") as well as with a sufficient interpersonal distance and through a collective mode (i.e. imagining them in terms of "how they can be"). Participants used narrative and theatre to identify and conceptualize problems. According to Vince (2002), critical reflection is only possible when various types of resistance become "visible" to participants. "Visible" means that participants can put the pieces of personal experiences into an articulate and meaningful interpersonal organizational context. This can be difficult to do via traditional managerial training techniques, but through the use of role-play and imagination, new outlooks and perceptions can be generated in order to provide all stakeholders with innovative solutions and courses of action that otherwise would not have been achieved (Marshak and Grant, 2008; Abma, 2003; Reissner, 2008).

\section{Giving Voice To The Stakeholders: The Case Study}

Boal (1995) describes acting out and reflecting upon embodied experiences and perplexed situations through "voicing thoughts." This approach was applied over a period of three months, between February and April 2012, by Executive Education representatives from ESC Rennes. They worked extensively with the management of ERDF in order to identify what the clear focus of the training should be. Based on these pre-planning interviews, structured brainstorming sessions and workshops, ESC Rennes proposed an action-based learning initiative consisting of six two-and-a-half-day training sessions. The developed programme provided participants with a "knowledge framework" blending improvisational theatre, up-todate customer relationship management strategies and industry best practices. The training 
took place between May and December 2012. Figure 1 provides a complete timeline of the project.

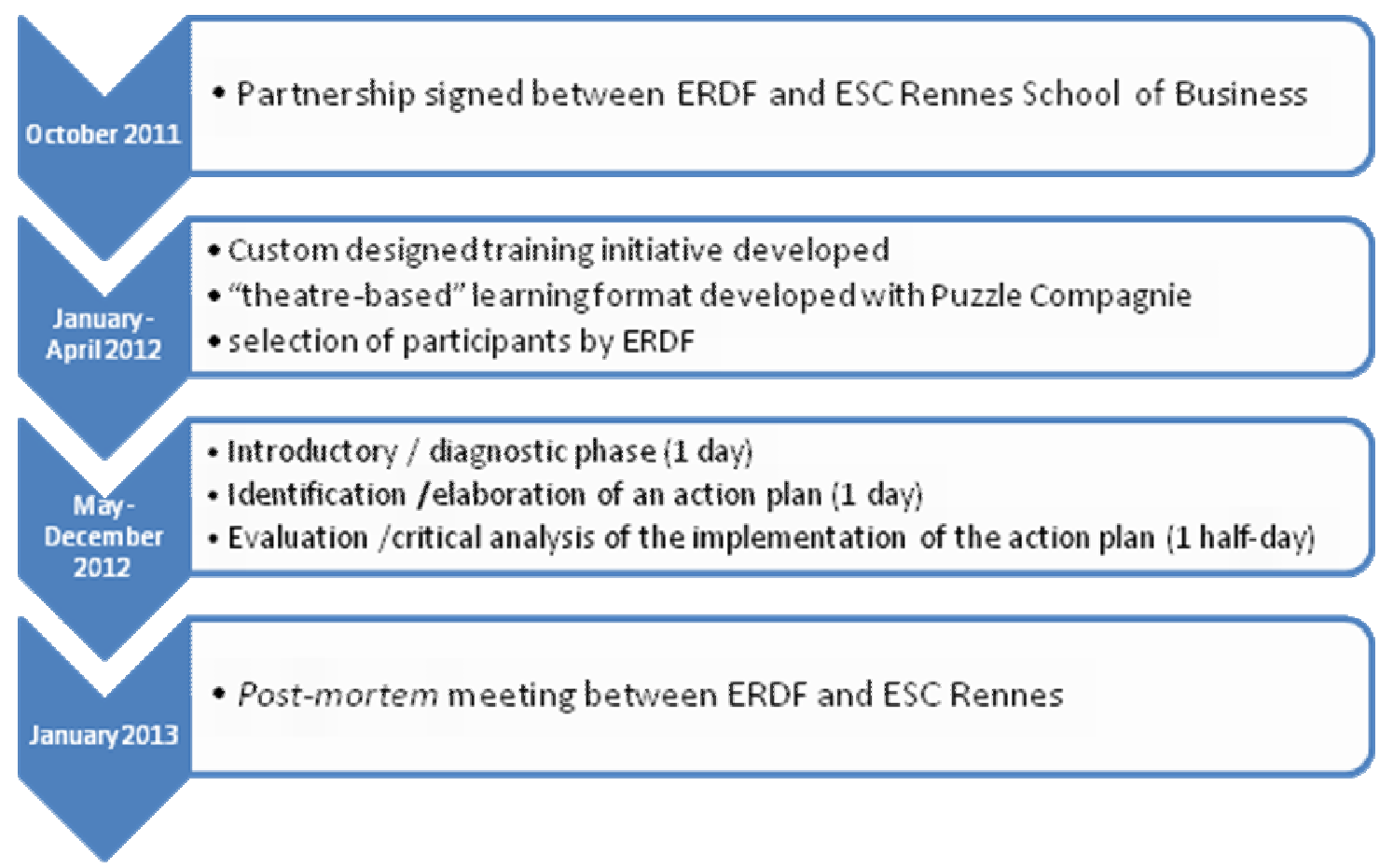

Fig. 1: Timeline of the theatre-based learning initiative between ERDF and ESC Rennes

Six two-and-a-half-day training sessions were conducted from May to December 2012, involving 70 ERDF employees. They were divided into groups of eight to twelve people each. The groups were deliberately comprised of both blue collar in-field technicians and white collar business development specialists and engineers. This diversity was encouraged, for it was deemed as being useful in acting as a catalyst towards creating inter-personal dialogue, which in conjunction with theatre techniques, would allow for both the expressing and challenging of individual views, attitudes and effective behaviour. The use of post-Boalian TBL allowed for sensing, sharing, repeating, amplifying and interpreting perplexity of intertwined former and current work processes. The group dynamics, i.e. the interactive behavioural effects and factors that arise as a result of people working closely together (Allport, 1948; Bargal and Bar, 1992), were further enhanced by the fact that some of the employees were former workers from the parent company EDF and therefore had a "legacy" or "institutional" outlook. Other employees were former technicians who had been promoted to business engineers, while some were new recruits from outside the company. The theatrical methods developed and employed allowed participants to explore the many different possible meanings hidden behind individual experiences, and to look for generalized solutions. This was made possible by the fact that the researchers and actors provided the internal stakeholders with a creative yet safe and transparent reflexive environment.

Two improvisational theatre formats were chosen by the facilitators; "improvisational wrestling" and "improvisational cabaret." These two theatrical formats were created by Robert Gravel and Yvon Leduc, with the founding of their improvisational group the "Ligue nationale d'improvisation" (LNI) in Montreal, Canada (Feral, 1983). To the best of our knowledge, these two elements have never been used before in a TBL format. Therefore, a decision was made to test them by making them a key component of an innovative research 
framework. As the name implies, in improvisational wrestling two actors "fight" verbally and artistically in a "ring" based on topics suggested by the "spectators" (the participants of the training initiative). The length of improvisation varies from between 3 to 10 minutes and there is a "referee" (the participant who suggested the performed topic).

As the name implies, in improvisational wrestling two actors "fight" verbally and artistically in a "ring" based on topics suggested by the "spectators" (the participants of the training initiative). The length of improvisation varies from between 3 to 10 minutes and there is a "referee" (the participant who suggested the performed topic).

Improvisational cabaret is an alternative, and calmer, form of improvisational wrestling. It is much simpler and easier to organize and run (with there being no "rink" or "referees"). The group participants are the ones who determine the topics and the way the improvisation should be performed (in the format of a musical, drama, comedy, etc.). Here, the actors invited participants to take part in the improvisational exercises and sketches.

The logic behind using the above two methods was to provide the non-homogeneous groups with experiential and transformative theatrical arts-based processes/techniques. This involved the use of:

- Projective techniques: revealing tacit and embodied collective knowledge as well as individual inner feelings and hidden unconscious processes.

- Critical reflection: identifying and raising awareness of social / inter-professional structures inside the organisation in order to discover various process and structural overlaps.

- Generative questioning: exploration and understanding of how individuals inside the organisation experience various aspects of issues or phenomena.

It was clear to ERDF management that many employees at different levels of the company had difficulty identifying and communicating what exactly the "new rules of the game" were in this deregulated environment. Furthermore, it was felt that legacy employees were not always as comfortable in their positions as they were when they were part of EDF and working for a state-owned service provider. Management believed that this "nostalgia" for the past had to be somehow converted into excitement for the future in order to bring about positive and effective change in the company's corporate culture and the way that employees dealt with customers.

ERDF was confident that the programme provided by the ESC Rennes expert team would help to achieve these goals. It "broke" the classical linear analytical approach in current management processes at ERDF and introduced an innovative and holistic process based on collective interpretation and theatre-assisted learning. As a result, TBL narratives and performances facilitated the framing of new and shared meanings, providing the stakeholders with a self-understanding that allows for an accelerated collective mind-set change (Ford and Ford, 1995; Mashak and Grant, 2008) (see fig. 2). 


\begin{tabular}{|c|c|c|}
\hline & $\begin{array}{l}\text { Linear Analytical Approach } \\
\text { (Classical Method) }\end{array}$ & $\begin{array}{l}\text { Holistic Interpretative Approach } \\
\text { (Theatre-based learning Method) }\end{array}$ \\
\hline Focus & $\begin{array}{l}\text { On a project with precisely } \\
\text { defined timeline }\end{array}$ & On a process which is open-ended \\
\hline Thrust & $\begin{array}{l}\text { To solve problems defined for the } \\
\text { project }\end{array}$ & $\begin{array}{l}\text { To troubleshoot process malfunctions } \\
\text { and develop corrective actions, share } \\
\text { best practices }\end{array}$ \\
\hline Goals & Set by line managers & $\begin{array}{l}\text { Are ambiguous, evolve during the } \\
\text { process }\end{array}$ \\
\hline Managers & $\begin{array}{l}\text { "Command and Control" issuing } \\
\text { of orders in order to resolve } \\
\text { CRM* problems }\end{array}$ & $\begin{array}{l}\text { Line managers are "invited" to share } \\
\text { the subordinates' problems } \\
\text { encountered and to explore ambiguity } \\
\text { in CRM* }\end{array}$ \\
\hline Communication & $\begin{array}{l}\text { Is based on precise, technical } \\
\text { exchange of information }\end{array}$ & $\begin{array}{l}\text { Is context-dependent, using } \\
\text { metaphors and semi-determined. }\end{array}$ \\
\hline
\end{tabular}

* Customer Relationship Management

Fig. 2: A comparison of the classical "Linear Analytical" approach to problem solving vs. a "Holistic Interpretative Approach" (Adapted from Ford and Ford, 1995; Mashak and Grant, 2008)

The management of ERDF was confident that employees would start thinking in new and positive ways about the client culture through an original and fun training programme such as this one.

Each session was facilitated by a professor from ESC Rennes and two artists from Puzzle Compagnie. The sessions were divided into three stages:

1. Introductory / diagnostic phase - one day spread out over two consecutive half-day sessions.

2. Identification / elaboration of an action plan - one day comprised of a morning and afternoon session.

3. Evaluation / critical analysis of the implementation of the action plan - one half-day session.

\subsection{The Training Initiative - Phase 1}

In the first stage, a lively diagnostic was performed using theatrical formats. This was based on the idea that theatre creates a type of "meta-language" that allows and/or reinforces the generation of dialogue by "making thought visible" (Bohm, 1996; Watzlawick, 1976; Hayakawa \& Hayakawa, 1990). Meta-language has been successfully used in the past with people who have undergone stress or who have been exposed to stressful situations or environments that Boal (1995) called "internal hardships" (e.g. people living in economically challenged areas, or under repressive regimes, or who have been addicted to drugs).

The first half-day was designed so that the participants could work alternatively in small groups and open forums. This module was conjointly run by a professor from ESC Rennes 
and the actors from Puzzle Compagnie. Its aim was to trigger in the participants a sense of ownership and interest in the targeted ERDF organisational structure, management, and customer oriented culture. The function of improvisational theatre was to act as a catalyst for change and positively engage the participants.

The participants were encouraged to identify and outline problems, or to recall recent negative events that they were either involved in or witnessed happening to someone else. They were encouraged to express their feelings, both negative and positive, about the current organization's management and in-house customer relationship programme. The purpose was to stimulate dialogue within the group through improvisational theatre.

In the second half-day, the themes and narratives that were written down previously were conceptualized and played out in a two-stage format. First, the actors alone performed short three to five-minute "wrestling scenes" drawn from the freely expressed participants' ideas. The fact that it was the actors who played the roles of participants facing difficult customer relationship issues with phantom customers allowed the participants to disengage themselves from the context and the specific elements of the problem at hand. They were then able to focus on the underlying "inter-textual" hidden agenda issues and progressively channel an intuitive yet logical and emotionally sound understanding of the current way customer relationships are managed at ERDF. The learning and skills focus of this second half-day session was on increasing the participants' willingness to participate in knowledge creation and understanding.

\subsection{The Training Initiative - Phase 2}

After this introductory / diagnostic phase composed of art-based exercises, it was believed that the participants were comfortable and had entered what the facilitators referred to as a "reflection zone, with the observation being that this opened up new perspectives based on their own experiences. The goal here was not to confront issues but to reframe them through art, allowing for critical observation, the expression of unconventional ideas and the generation of innovative solutions without fear of reproach. This stage is vital in that it has been argued that a lack of reflection with regards to the way people interact and communicate can be a major contributor to why change management initiatives fail (Pieters et al., 2012).

The morning session of the second stage was devoted to the identification and elaboration of an action plan. The facilitators identified and introduced a conceptual framework that would give the participants a mechanism for engaging in critical reflection (see fig. 3). 


\begin{tabular}{|c|c|c|c|}
\hline Characteristics & Focus & Goal & Key elements to pursue \\
\hline $\begin{array}{l}\text { To identify and } \\
\text { question the } \\
\text { established and } \\
\text { taken-for-granted } \\
\text { beliefs and } \\
\text { processes }\end{array}$ & $\begin{array}{l}\text { To question } \\
\text { and challenge } \\
\text { existing } \\
\text { practices }\end{array}$ & $\begin{array}{l}\text { 1. To critically evaluate and } \\
\text { transform processes through } \\
\text { improved competences linked to } \\
\text { productivity and customer } \\
\text { satisfaction } \\
\text { 2. To generate work and learning } \\
\text { frameworks that would lead to } \\
\text { improved work satisfaction, } \\
\text { quality, and a better overall } \\
\text { professional life }\end{array}$ & $\begin{array}{l}\text { 1. Increased autonomy and } \\
\text { employee empowerment } \\
\text { 2. Pride in providing excellent } \\
\text { quality of customer service } \\
\text { through professional and clear } \\
\text { procedures } \\
\text { 3.Transformation of } \\
\text { organisational procedures linked } \\
\text { to the delivery of customer service } \\
\text { and customer satisfaction }\end{array}$ \\
\hline
\end{tabular}

Fig. 3: Conceptual framework for the second stage of the theatre-based learning initiative (Adapted from Cunliffe 2009 and Reynolds 2011)

The second stage also involved the understanding of key issues and elaboration of a concrete action plan to deal with the problems and issues identified in the previous two half-day sessions. Thus, the participants were asked by the ESR Rennes facilitator to individually prepare answers to three questions based on their understanding of the current unsatisfactory situation expressed during the art-based exercises:

- What is a sustainable satisfactory customer relationship? Provide a definition and be sure to justify your answer.

- Does the above definition allow you to evaluate your strengths and weaknesses as of today? Does it allow you to make a statement about ERDF's competitive position and value proposition?

- Are you confident about the customer solutions / products / services that ERDF offers to its clients? What other solutions / products / services would you propose to your clients today so that they would remain your clients tomorrow as well?

The individual answers were then shared with the group and the facilitators. The actors challenged some of the ideas by engaging in sharp and short improvisations with the "owners" of identified problems and proposed solutions/products/services.

In the afternoon session of the "action plan" stage, the professors briefly introduced some customer relationship theory and the latest best practices, as well as other similar companies' best practices, and related it to in-house ERDF practices. They then invited the participants to contribute to the creation of a metaphorical "tool box" composed of:

- A New Paradigm: a vision of what an ideal and genuine ERDF customer relationship managerial culture would consist of.

- A Road Map: prioritizing goals, actions, and best practices in order to reach the above customer relationship managerial culture.

- Knowledge creation related to the collective corporate memory of past EDF practices, but at the same time trying to be future oriented in order to build a genuine customer relationship culture that all stakeholders would be proud of. 
- Evaluation of the means to reach the prioritized goals.

Within a week after completion of this module, the participants and the management of ERDF were provided with a document that was formulated and synthesized from all of the previous experiences and interactions that took place in the preceding training sessions. It contained both the collective knowledge co-built during the first two days of the programme and a customized individual action plan for each participant.

\subsection{The Training Initiative - Phase 3}

The third phase involved an evaluation of the implementation of the customized action plans. Two months after the second stage, the professors of ESC Rennes conducted a half-day "After session" intervention which allowed participants to amend and adjust the initial "tool box" and provide feedback on both the individual and collective progress that they believe had been made. The facilitator team was composed of one professor and one actor. The facilitators first refreshed the participants' memories using a five-step process of dialogue based on the application of theatre-based methods of enquiry (Beck et al 2011). The group members were asked to:

1. Recall their past experiences in writing, narration and the sharing of ideas.

2. Recall the benefit of being collectively involved in the process of sharing and exploring different ideas.

3. Think about the experience of exploring and reflecting.

4. Recall the generating of innovative solutions.

5. Focus on the analysing of ideas.

It was noticed that the vast majority of the participants were eager and proud to provide testimonials about their improvements and willingness to take part in all of these steps, as well as to prepare theatrical sketches that showed the evolution of their customer relationship managerial structures / processes / practices.

\section{Results \& Findings}

The outcomes of the customized "theatre-based" learning initiative were positive overall, as almost all of the objectives set forth at the beginning of the proposal were achieved. Based on feedback and observations from ERDF management, the initiative is considered as having successfully resulted in a noticeable improvement with regards to:

- What employees believe, and what they identify, a sustainable and satisfactory customer service relationship to be. 
- The ability of employees to provide solutions / products / services specifically tailored to individual customers that will result in maximum value and a positive experience for the client.

- Employee motivation as it relates to getting actively involved in the evolution of ERDF's corporate culture.

ERDF believes that through this training initiative it was able to instil in its employees a sense of empowerment, i.e. a more autonomous team-based management style. The managers impressed upon employees the point that their creativity and initiatives, with regards to customer relationship management, mattered. In the weeks following the theatre-based learning programme it was observed that a significant number of proposals were generated by the "newly empowered" employees.

Among the most frequently cited useful practices / tools to be developed as a result of the training, as suggested by the participants themselves, were the following:

- Creation of an open-source portfolio of sales and after-sales selling points stemming from in-house best practices.

- Identification of the need to get further training in customer relationship management.

- Organize regular collective debriefing sessions so to avoid "mission creep" and employees becoming too attached to one particular customer, possibly losing sight of overall corporate objectives.

- Development of a customer based problem solving decision matrix (see fig. 4).

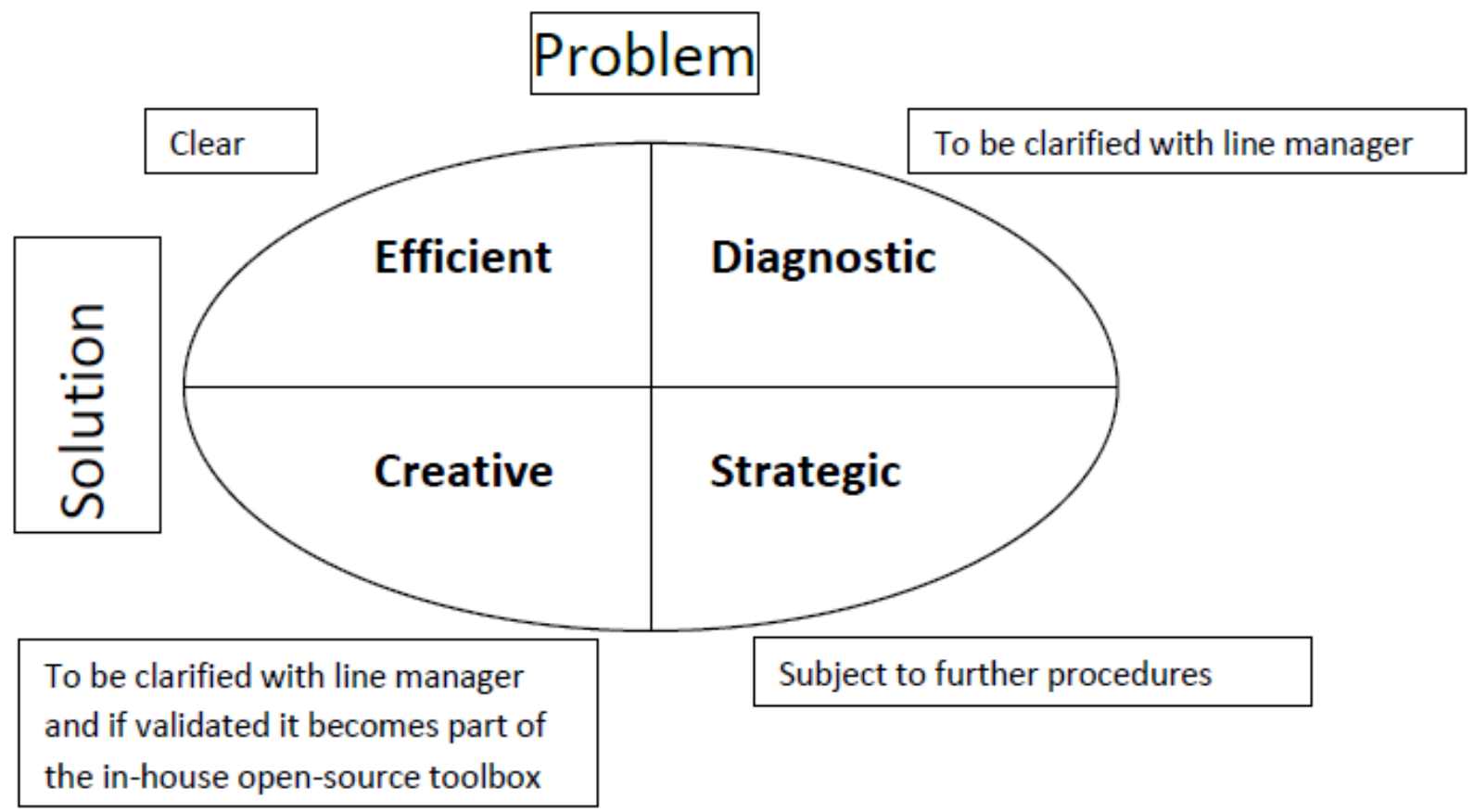

Fig. 4: 4-box problem solving decision matrix 
As for the employees themselves, extremely high levels of satisfaction were noted, with the vast majority of participants reportedly being either satisfied or very satisfied with the training's outcomes (see fig. 5).

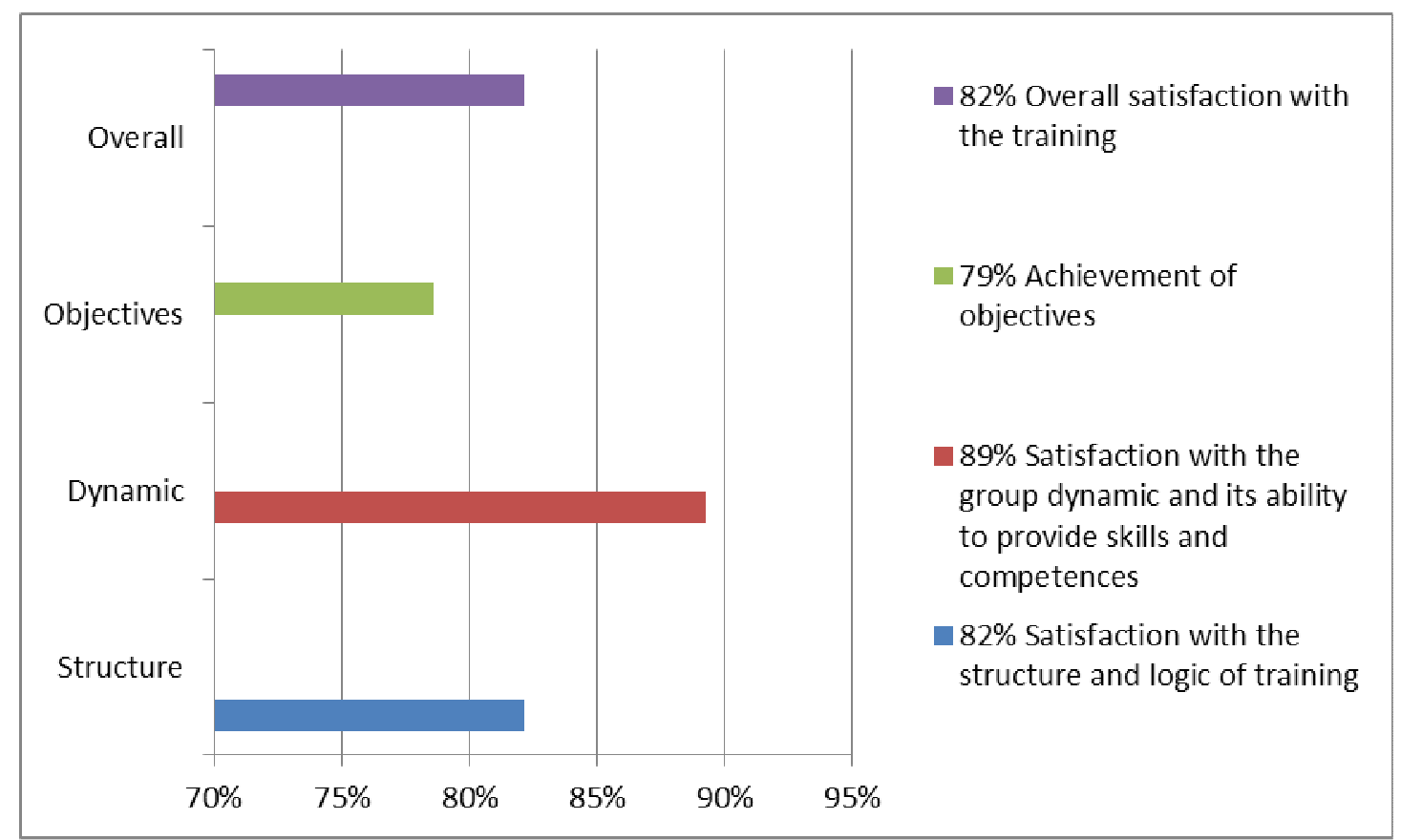

Fig. 5: Survey of the Participants' satisfaction with the training initiative

The facilitators and ERDF management observed a significant increase in the participants' capacity to engage in both individual and collective self-evaluation and, as a result, better develop innovative solutions with regards to the way they manage customer service relationships.

\section{Conclusion}

ERDF management highlighted the fact that this training initiative allowed the participants to understand ERDF's goals and contributed to creating an esprit de corps. Management believed that the collective goodwill derived from the exercise was critical for boosting individual levels of motivation, raising morale, increasing productivity and lowering costs, all resulting in overall higher levels of customer satisfaction.

Furthermore, ERDF-West made significant progress with regards to their stated objective of making the transition from a traditional public service oriented organization to a more teambased customer service oriented one (see fig. 6).

\begin{tabular}{|l|l|}
\hline $\begin{array}{l}\text { Traditional Organization } \\
\text { (Public Service Oriented) }\end{array}$ & $\begin{array}{l}\text { Team-based Organization } \\
\text { (Team-based Customer Oriented) }\end{array}$ \\
\hline Management driven and controlled & Customer Driven and team regulated \\
\hline Information flow is top-down and limited & Information abundant and shared \\
\hline Many levels of management & Limited levels of management \\
\hline Linear incremental organizational changes & Continuous organizational improvements \\
\hline Seemingly organized & Seemingly chaotic \\
\hline
\end{tabular}


High management commitment through the

use of authority

Fig. 6: Evolution of corporate culture and organizational behaviour at ERDF (adapted from Weick 1979, 1995, Weick and Quinn, 1999)

During the post-mortem meeting between ERDF and ESC Rennes held in January 2013, it was estimated that 20 per cent of participants were what could be described as "early adopters" and jumped eagerly at the offered opportunity for empowerment. 75 per cent of participants, according to ERDF management, accepted empowerment and were able to thrive under it. Unfortunately, 5 per cent were deemed as being "left out," unable to move past their "nostalgia for the good old days." People in this group can often see change as a "generator of chaos" (Fronda and Moriceau, 2008).

Changing the existing culture of any institution is a difficult endeavor, usually met with extremely low success rates (Smith, 2003; Burnes, 2009; Senturia et al., 2008; Rogers et al., 2006). A study done by McKinsey and Company (2008) showed that almost two-thirds of change management initiatives failed to achieve the results management desired, with failure rates on the order of $70 \%$ being generally accepted as the norm found in practice (Wall, 2005; Werkman, 2009). In spite of this, ERDF believes that the skills, competences and abilities that their employees developed and acquired during the training initiative will be crucial in bringing about the effective change in corporate culture that it desires. Furthermore, the contents of the "tool box," when combined with the new found sense of employee empowerment / ownership, will make, according to ERDF management, the programme of change management sustainable and self reinforcing.

As one of the participants stated, it was "something I have been waiting to be able to do for a long time."

\section{References \& Bibliography}

Abma, T. (2003). Learning by telling storytelling workshops as an organizational learning intervention. Management Learning 34: 221-240.

Allport, G.W. (1948). Foreword, in Lewin, G.W. (Ed.), Resolving Social Conflict, Harper and Row, London.

Bargal, D. and Bar, H. (1992). A Lewinian approach to intergroup workshops for Arab-Palestinian and Jewish Youth. Journal of Social Issues 48(2): 139-154.

Barry, D. and Meisiek, S. (2010). Seeing More and Seeing Differently: Sensemaking, Mindfullness, and the Workarts. Organisation Studies 31 (11): 1505-1530.

Beck, J.L., Belliveau, G., Lea, G.W. and Wager, A. (2011). Delineating a Spectrum of Research-Based Theatre, Qualitative Inquiry 17(8): 687-700.

Bingham, L., Blomgren, T. N., O'Leary, R.. (2005). The New Governance: Practices and Processes for Stakeholder and Citizen Participation in the Work of Government. Public Administration Review 65(5): 547-58. 
Biron, M. and Bamberger, P. (2010). The impact of structural empowerment on individual well-being and performance: Taking agent preferences, self-efficacy and operational constraints into account. Human Relations, 63: 163-191

Boal, A. (1995). The rainbow of desire. (A. Jackson, Trans). London. Routledge.

Boyte, H. C. (2005). Reframing Democracy: Governance, Civic Agency, and Politics. Public Administration Review 65(5): 536-46.

Bohm, D.(1996). On dialogue. London:Routledge.

Bowen, D. E. and Lawler, E. E. (1995). Empowering Service Employees. Sloan Management Review, 36:73-84.

Burnes, B. (2009). Managing Change, 5th ed., FT/Prentice Hall, London.

Cunliffe, A.L. (2009). The Philosopher Leader: On Relationalism, Ethics and Reflexivity - A Critical Perspective On Teaching Leadership. Management Learning 40(1): 87-101.

Directive 96/92/EC of the European Parliament and of the Council of 19 December 1996 concerning common rules for the internal market in electricity. Available at: http://eurlex.europa.eu/LexUriServ/LexUriServ.do?uri=CELEX:31996L0092:EN:HTML

Directive 2003/54/EC of the European Parliament and of the Council of 26 June 2003 concerning common rules for the internal market in electricity. Available at: http://eurlex.europa.eu/LexUriServ/LexUriServ.do?uri=CELEX:32003L0054:EN:HTML

Directive 2009/72/EC of the European Parliament and of the Council of 13 July 2009 concerning common rules for the internal market in electricity. Available at: http://eurlex.europa.eu/LexUriServ/LexUriServ.do?uri=OJ:L:2009:211:0055:0093:EN:PDF

Feral, J (1983) LNI : Ligue nationale d'improvisation. The Drama Review: TDR 27(1): 97-100

Fernandez, S. and Moldogaziev, T. (2013). Using Employee Empowerment to Encourage Innovative Behavior in the Public Sector. Journal of Public Administration Research and Theory, 23 (1): 155-187.

Fernandez, S. and Moldogaziev, T. (2011). Empowering Public Sector Employees to Improve Performance: Does it Work? American Review of Public Administration, 41: 23-47.

Fronda, Y and Moriceau, J-L. (2008). I am not your hero: change management and culture shocks in a public sector corporation. Journal of Organizational Change Management 21(5): 589-609 
Halvorsen, T., Hauknes, J., Miles, I., and Røste, R. (2005). On the differences between public and private sector innovation PUBLIN Project, report D3, Oslo: STEP. Available at: http://www.step.no/publin/reports.html

Gherrardi, S. (2006). Organizational Knowledge: The Texture of Workplace Learning. USA: Blackwell Publishing.

Gibbons, M., Limoges, C., Nowotny, H., Schwarzman, S., Scott, P. and Trow, M. (1994). The New Production of Knowledge. London: Sage.

Hayakawa, S. I., and Hayakawa, A. (1990). Language and thought in action (5th ed.). SanDiego, CA: Harcourt Brace \& Co.

Jääskeläinen, A. and Lönnqvist, A. (2011). Public service productivity: how to capture outputs? International Journal of Public Sector Management, 4 (4): 289 - 302

Kettl, D.F. (2005). The Global Public Management Revolution: A Report on the Transformation of Governance. Second Edition. Washington, DC: Brookings Institution Press.

Kim, S. (2002). Participative Management and Job Satisfaction: Lessons for Management Leadership. Public Administration Review, 62: 231-241.

Marshak, R.J. ad Grant, D. (2008). Organizational Discourse and New Organization Development Practices. British Journal of Management 19: 7-19.

McKinsey and Company (2008). Creating organizational transformations, The McKinsey Quarterly, July, pp. 1-7, available at: www.mckinseyquarterly.com

Nisker, J. (2008). Health-Policy Research and the Possibility of Theatre, in J.G. Knowles and A.L. Cole (Eds.) Handbook of the Arts in Qualitative Research. Thousands Oaks, pp. 613-623. CA: Sage.

O‘Flynn, J. (2007). From New Public Management to Public Value: Paradigmatic Change and Managerial Implications.\|Australian Journal of Public Administration, 66: 353-366.

Oikarinen, T., Pässilä A. and Vince, R. (2011) 'The Role of Reflection, Reflection on Roles: Practice-based innovation through theatre-based learning', in Helina Melkas and Vesa Harmaakorpi (Eds.) Practice-based Innovation: Insights, Applications and Policy Implications, Helsinki: Springer.

Perry, J.L., Mesch, D., and Paarlberg, L. (2006). Motivating Employees in a New Governance Era: The Performance Paradigm Revisited. Public Administration Review, 66: 505514.

Pieters, J., H., Caniëls, M., J., C., and Homan, T. (2012). Professional discourses and resistance to change, Journal of Organizational Change Management 25(6): 798-818

Reissner, S.C. (2008). Narratives of organisational change and learning making sense of 
testing times. Cheltenham, UK \& Northampton, US: Edward Elgar.

Reynolds, M. (2011). Reflective Practice: Origins and Interpretations. Action Learning: Research and Practice 8(1): 5-13.

Rogers, P., Meehan, P. and Tanner, S. (2006). Building A Winning Culture, Bain and Company, Boston, MA.

Saldaña, J. (2008). Ethnodrama and Ethnotheatre, in N. K. Denzin and Y. S.Lincoln (eds.) The SAGE Handbook of Qualitative Research, pp. 195-208. Thousand Oaks, CA: Sage.

Senturia, T., Flees, L. and Maceda, M. (2008). Leading Change Management Requires Sticking to the PLOT, Bain and Company, London.

Smith, M.E. (2003). Changing an organization's culture: correlates of success and failure, Leadership and Organization Development Journal 24( 5): 249-261.

Soparnot, R. (2012). The concept of organizational change capacity, Journal of Organizational Change Management 24(5):. 640-661

Vince, R. (2002) ‘Organizing reflection’, Management Learning 33: 63-78.

Vince, R. and Reynolds, M. (2009). Reflexion, Reflective Practice and Organizing Reflection, in Armstrong, S.J. and Fukami, C.V. (Eds.) The Sage Handbook of Management Learning, Education and Development. London: Sage.

Walker, R. M., Damanpour, F. and Devece, C. A. (2011). Management Innovation and Organizational Performance: The Mediating Effect of Performance Management.\| Journal of Public Administration Research and Theory, 21: 367-386.

Wall, S.J. (2005). Looking beyond the obvious in merger integration. Mergers and Acquisitions 40(3): 41-46.

Watzlawick, P. (1976). How real is real? New York: Random House.

Weick, K. (1995). Sensemaking in Organisations. London: Sage.

Weick, K. E., \& Quinn, R.E. (1999). Organizational change and development. Annual Review Psychology, 50, 361-386.

Werkman, R.A. (2009). Understanding failure to change: a pluralistic approach and five patterns. Leadership and Organization Development Journal 30(7): 664-84.

White, V. and Belliveau, G .(2010). Whose Story Is it Anyway? Exploring Ethical Dilemmas in Performance Research, Performing Ethos International Research Journal 1(1): 8595.

White, V. and Belliveau, G. (2011). Multiple Perspectives, Loyalties and Identities: Exploring 
Intrapersonal Spaces through Research-Based Theatre, International Journal of Qualitative Studies in Education, 24(2): 227-238. 


\section{Irena Descubes}

ESC Rennes School of Business

Rennes

France

\section{Tom McNamara}

ESC Rennes School of Business

Rennes

France

Corresponding author: Irena Descubes

$\mathrm{X}$ Please check this box if you do not wish your email address to be published

\section{Biographical Details:}

Irena Descubes is Assistant Professor of Marketing and Manager of Collège des Hautes Etudes du Développement Durable (CHEDD) at ESC Rennes School of Business. Her research is driven by her interest in sustainable economic transition and societal change. Her work has been published in the Journal of Euromarketing and in the Strategic Change.

Tom McNamara is Assistant Professor of Operations Management at the ESC Rennes School of Business, France, and a former Visiting Lecturer at the French National Military Academy at Saint-Cyr, Coëtquidan, France. Previous to academia, he worked at a Fortune 500 (C) energy company. His current research interests include issues and trends in Production Management, with a focus on sustainability. 